\title{
COMBINED MITRAL AND AORTIC VALVE REPLACEMENT: PROGNOSTIC FACTORS AFFECTING EARLY AND INTERMEDIATE OUTCOME
}

\author{
By \\ Abed A. Moawafy, M.D. Ahmed Kadry Abdalla, M.D. \\ Reda Aboulmaaty, M.D. Nasr L. Gayed, M.D.
}

From

Department of Cardio-Thoracic Surgery, Faculty of Medicine, Mansoura University, Mansoura, Egypt.

\section{ABSTRACT}

Affection of both mitral and aortic valves is a common finding in rheumatic heart diseases, and when severe, it may necessitate replacement of both valves simultaneously. This study discusses factors affecting early and intermediate outcome after combined mitral and aortic valve replacement with or without tricuspid valve repair. The study included 55 patients, 37 of them $(67.3 \%)$ were males and $18(32.7 \%)$ were females. Their mean age was 29.96 ( 8.44 years with 20 patients $(36.4 \%)$ of them under 25 years age. There were $7(12.7 \%)$ hospital mortalities, two of them (3.6\%) were operative mortalities. The factors that was found to be significant for early mortality were presence of AF $(P=0.002)$, advanced NYHA class $(P=0.02)$, low $E F(P=0.005)$, low FS $(P=0.005)$, and high MPAP $(P=0.001)$. In the follow up period that ranged between 3 and 60 months, complications occurred in 14 patients $(29.2 \%)$, in the form of 5 endocarditis, 4 persistant heart failure, 3 thromboembolic events, and 2 anticoagulation related bleeding. There was 5 late mortalities $(10.4 \%), 3$ due to endocarditis and 2 due to persistent heart failure. The factors that were significant in predicting intermediate outcome were non-improvement of NYHA functional class $(P=0.002)$, nonperformance of mitral valve preservation ( $P=0.003$ ), occurrence of complication ( $P=0.001)$, development of arrhythmia $(P=0.012)$, persistence of low ventricular performance $(P=0.003)$, and persistence 
of elevated MPAP $(P=0.001)$. The actuarial suivival of the patients was $83.4 \%$ after one year and $73.79 \%$ after 5 years. We concluded that combined mitral and aortic valve replacement in our series is an operation that carries a mortality and morbidity not much higher than what is reported. We recommend it to be done as early as possible to patients with double valve lesion before irreversible myocardial damage occurs. We have also shown that significant factors affecting both early and intermediate outcome are mainly related to advanced functional class of the patient and disease effect on cardiac status.

\section{INTRODUCTION}

Although rheumatic fever was thought to be nearly eradicated from developed countries, it continues to be a challenge because of its high prevalence in the developing world. In addition, new aspects have emerged and are a cause of concern, as indicated by the recent outbreak in industrial countries. (1)

In many areas of the third world, valvular diseases that follows rheumatic fever progresses rapidly and reluntlessly resulting in disability and death. Therefore an aggressive Vol. 32, No. 1 \& 2 Jan. \& April, 2001 policy has been pursued and valve replacement is considered a more desirable treatment option (2).

Simultaneous replacement of both aortic and mitral valves was performed for the first time almost 40 years ago, and since then combined mitral and aortic valve replacement (MAVR) has become a quite common surgical procedure (3).

Compared with single valve replacement, combined mitral and aortic valve replacement (MAVR) represents a major technical challenge (2).

Our clinical experience with patients who underwent MAVR with or without tricuspid valve repair over a 5 year period forms the basis of this article with special attention to factors that may affect early (within 3 months) and intermediate (mean follow-up of 27.5 months) postoperative outcome was conducted

\section{PATIENTS AND METHODS}

This study at the Cardiothoracic Surgical Department, Mansoura University Hospital, throughout a 5 year period from January 1996 to December 2000 . 
The study included 55 patients for whom combined mitral and aortic valve replacement was performed with or without tricuspid valve repair. There was 37 male patient $(67.3 \%)$ and 18 female patient (32.7\%) (male / female ratio 2.1:1). The age of the patients ranged between 15 and 45 year, with a mean age of $29.96 \pm 8.44$ years, and twenty patients of them $(36.4 \%)$ were below the age of 25 years. There was a definite history of previous rheumatic fever in 51 patients $(92.7 \%)$.

The duration of symptoms of 54 patients ranged between 2 and 7 years with a mean of $4.1 \pm 1.5$ years. The remaining patient was referred to us from the Obstetric Department with acute right embolic hemiplegia as her first presentation with only two weeks duration during her twenty-second week of pregnancy.

The most common symptom was dyspnea followed by cough, palpitation and easy fatiguability. Other symptoms are listed in Table 1.

All patients belonged to either New York Heart Association (NYHA) functional class III (76.4\%) or IV (23:6\%).
Plain chest $x$-ray films were done for ali the patients in postero anterior and lateral views with special attention to the cardio-thoracic ratio which ranged between $50 \%$ and $90 \%$ with a me: $37.2 \% \pm 10.83 \%$, and radiological signs of pulmonary congestion that was positive in 26 patients $(47.3 \%)$. Electrocardiography was also done for all the patients and it showed atrial fibrillation in 25 patients $(45.5 \%)$. Echocardiography was the main investigation done for all the patients and its results, are shown in table 2.

According to the clinical and echocardiographic data, the patients were categorized into 3 groups; Group 1: with predominant mitral stenosis and aortic stensis (18 patients $32.7 \%$ ), Group 2: with predominant mitral regurgitation and aortic regurgitation ( 18 patients $32.7 \%$ ), and Group 3: with mixed mitral stenosis or regurgitation and aortic stenosis or regurgitaion (19 patients $34.6 \%$ ). There were 12 patients with additional tricuspid valve lesions $(21.8 \%)$, eight of them having organic tricuspid stenosis or regurgitation.

The mitral valve area was estimated in patients with severe and moder-

MANSOURA MEDICAL JOURNAL 
ate mitral stencsis (32 patients) and it ranged between 0.6 and $2.4 \mathrm{~cm} 2$ with a mean of $1.25 \pm 0.36 \mathrm{~cm} 2$. Also the gradient across the aortic valve was estimated in patients with severe and moderate aortic stenosis (28 patients) and it ranged between 50 and 110 $\mathrm{mm} \mathrm{Hg}$. with a mean of $83.7 \pm 17.2$ $\mathrm{mm} \mathrm{Hg}$.

\section{Operative Technique:}

All patients were operated upon through classic median sternotomy and routine aorto-bicaval cannulation. Cardiopulmonary bypass was accompolished utilizing a membrane oxygenator. Moderate systemic hypothermia $\left(28^{\circ} \mathrm{C}\right)$ to decrease noncoronary collateral return was employed routinely. Myocardial protection was offered by instillation of antigrade cold blood cardioplegia given through the coronary ostea that was repeated every 20 to 25 minutes. Improved protection of the ventricles was provided by the use of topical hypothermia with saline at $4^{\circ} \mathrm{C}$ or ice slush. All the patients had their aortic and mitral valves replaced using bileaflet mechanical valves. The mitral valve was replaced first, nevertheless the aortic valve was excised as the first step through the aortotomy. The sizes of the mitral valve prostheses inserted ranged between $23 \mathrm{~mm}$. and $33 \mathrm{~mm}$. with a mean of $28.1 \pm 2.3 \mathrm{~mm}$. There were 31 Carbomedics valve (56.4\%), 13 St. Jude valve $(23.6 \%)$ and 11 Orbis valve $(20 \%)$. The sizes of the aortic valve prostheses inserted ranged between $19 \mathrm{~mm}$. and $27 \mathrm{~mm}$. with a mean of $21.5 \pm 2.1 \mathrm{~mm}$. There were 34 Carbomedics valve (61.8\%), $16 \mathrm{St}$. Jude valve $(29.1 \%)$, and 5 Orbis valve $(9.1 \%)$. The posterior mitral valve leaflet was preserved whenever possible to maintain the geometry of the left ventricle and help improve the postoperative left ventricular performance, this was achieved in $31 \mathrm{pa}$ tients $(56.4 \%)$. The implanted valves were secured into position using interrupted horizontal mattress sutures 00 Ticron. The sutures were placed from above downwards to evert the annulus. The sutures were buttressed with Teflon pledgets whenever calcification of either the mitral or the aortic annulus was found. Tricuspid valve repair was an additional procedure in 8 patients (14.5\%) (2 with organic tricuspid stenosis and 6 with server tricuspid regurgitation), and this was usually done on a beating heart after the heart regained its contractility either spontaneously or with DC shock. The ischemic time (aortic cross clamp time) ranged between 70 minutes and 
137 minutes with a mean of $105.5 \pm$ 12.4 minutes. Patients were weaned off cardiopulmonary bypass using adrenaline. The weaning was easy in 6 patients $(11.3 \%)$ using less then 10C nanogram adrenaline, moderate in 30 patients $(67.9 \%)$ using between 100 and 300 nanogram adrenaline, and difficult in 11 patients $(20.8 \%)$ needing more than 300 nanogram of adrenaline. The cardiopulmonary bypass time ranged between $100 \mathrm{~min}$ utes and 200 minutes with a mean of $150.2 \pm 20.3$ minutes. Two of our patients died on table because of inability to wean them from bypass. The remaining 53 patients were transferred to the ICU where they were ventilated artificially for a period ranging between 3 and 72 hours with a mean of $12.4 \pm 11.8$ hours . The ICU stay of the patients $(53)$ ranged between 2 and 6 days with a mean of $4.28 \pm$ 0.87 days. The hospital stay of the patients ranged between 4 and 32 days with a mean of $16.78 \pm 6.84$ days. There was more five patients who died throughout their hospital stay and the other 48 patients were discharged for follow up.

The survived patients (48) were followed up in the outpatient clinic on monthly basis for the INR level and regular clinical examination. Echocardiography was done every six months, or whenever indicated. Mortality and morbidity were recorded along the guidelines of Edmonds and colleagues (4). The follow up period ranged between 6 and 60 months with a mean of $27.5 \pm 18.7$ months.

\section{STATISTICAL ANALYSIS}

All statistical data were tabulated and analyzed using Statistical Package for Social Science (SPSS). Values are expressed as the mean \pm standard deviation (SD). Chi-square was used for analysis of categorical data. For continuous variables, statistical analysis was performed using Studentís t-test. A P value $<0.05$ was considered statistically significant. Survival was estimated by the actuarial method and the calculated cumulative percentages of different patient groups were compared by the Log rank test.

\section{RESULTS}

Out of the 55 simultaneous mitral and aortic valve replacement performed, there was two operative moralities (3-6\%) Another five patients (9.1\%) died throughout their hospital stay with total hospital mortality of 7 patients $(12.7 \%)$. One of the two op- 
erative moralities was that pregnant lady with acute right embolic hemiplegia who was operated upon on emergency basis, and the other one was having a very low ejection fraction and markedly dilated left ventricle. The cause of hospital mortality of the other five patients was persistent myocardial failure in two (3.6\%), severe ventricular arrhythmia in one $(1.8 \%)$, cerbrovascular stroke in one $(1.8 \%)$, and multiple organ failure due to early prosthetic valve endocarditis in one $(1.8 \%)$. Table 3 shows the variables that were associated with hospital mortality and their significance.

At 5 years, the cumulative proportion survival curve of the patients according to their preoperative NYHA class (Fig.1), shows $52.34 \%$ survival for class IV patients and $80.74 \%$ survival for class III patients with a significant $P$. value of 0.04 .

Throughout the hospital stay of the surviving 48 patients, complications occurred in 11 patient $(22.9 \%)$. There were four cases $(8.3 \%)$ of wound infection, two of them were managed conservatively and the other two needed sternal reclosure. Two patients $(4.2 \%)$ developed postoperative pneumonia that was managed con- servatively. Two cases $(4.2 \%)$ of mild and moderate cerebral confusion subsided later on, and three cases (6.2\%) of arrhythmia were controlled medically.

Reoperation was performed for four patients $(8.3 \%)$, two of them for reclosure of clicky sternum and two for evacuation of pericardial collection causing postoperative tamponade.

Throughout the period of follow up of the alive 48 patients 14 complications occurred $(29.2 \%)$. There were five cases of prosthetic valve endocarditis, three of them died and the other two were managed conservatively, four cases of persistent heart failure $(8.3 \%)$, two of them died and the other two are still alive under antifailure treatment, three cases of minor non fatal thromboembolic complications $(6.2 \%)$, and two cases $(4.2 \%)$ of minor anticoagulation related haemorrhage which was easily controlled.

The total late mortality throughout the 5-year follow up period includes five patients $(10.4 \%)$. Three cases died because of endocarditis that presented 6,13 and 18 months after surgery. The second and third patients of them were reoperated for aortic valve 
rereplacement but died in hospital af- tion survival curve of the patients acter fifteen and seventeen days of sur- cording to their postoperative NYHA gery. Two more cases died of persis- class at the end of the follow up peritent heart failure seven and twenty od (Fig.2), shows $100 \%$ survival for one months after their surgery. Table class I, $75.76 \%$ for class II, $62.63 \%$ 4 summarizes the factors that may for class III and $0 \%$ for class IV with a have affected the postoperative out- highly significant $P$-value of 0.0003 . come and its significance.

The actuarial survival for all the

Most of the patients (81.3\%) were surviving 48 patients was $83.04 \%$ in NYHA functional class I or II (24 after one year, $78.62 \%$ after on one and 15 respectively) and the others $(18.7 \%)$ remained in class III or IV and were in need for continuous medical treatment. The cumulative proporand half years and $73.79 \%$ after two years which persisted stable till the end of the 5 years follow up period (Fig.3). 
Table 1: symptomatology of patients.

\begin{tabular}{|l|c|c|}
\hline \multicolumn{1}{|c|}{ Symptom } & Number & Percentage \\
\hline Dyspnea & 53 & $96.4 \%$ \\
\hline Cough & 45 & $81.8 \%$ \\
\hline Palpitation & 29 & $52.7 \%$ \\
\hline Fatigue & 26 & $47.3 \%$ \\
\hline Chest pain & 15 & $27.3 \%$ \\
\hline Recurrent chest infection & 14 & $25.5 \%$ \\
\hline Paroxysmal nocturnal dyspnea & 14 & $25.5 \%$ \\
\hline Heamoptysis & 9 & $16.4 \%$ \\
\hline Headache & 6 & $10.99 \%$ \\
\hline Embolic manifestation & 3 & $5.5 \%$ \\
\hline Dizziness & 3 & $5.5 \%$ \\
\hline
\end{tabular}

Table 2: Preoperative Echocardiographic data.

\begin{tabular}{|l|c|c|c|}
\hline Echo. data & Minimum. & Maximum & Mean \pm SD. \\
\hline LVESD (cm) & 3.6 & 7.0 & $4.32 \pm 1.06$ \\
\hline LVEDD (cm) & 4.1 & 9.2 & $6.36 \pm 1.26$ \\
\hline EF \% & 48 & 73 & $63.7 \pm 6.8$ \\
\hline FS & 21 & 48 & $32.6 \pm 4.7$ \\
\hline SWT $(\mathrm{cm})$ & 0.8 & 1.6 & $1.3 \pm 0.2$ \\
\hline PWT & 0.7 & 1.6 & $1.2 \pm 0.5$ \\
\hline LAD cm ${ }^{2}$ & 3.5 & 11.6 & $5.9 \pm 1.4$ \\
\hline MPAP mm Hg. & 35 & 70 & $55.5 \pm 5.4$ \\
\hline
\end{tabular}

SD: Standard deviation. LVESD: left ventricular end systolic diameter. LVEDD: left ventricular end diastolic diameter, EF: ejection fraction. FS: fractional shortening. SWT: septal wall thickness, PWT: posterior wall thickness, LAD: left atrial diameter, and MPAP: mean pulmonary artery pressure. 
Table 3. Comparison of different variables between hospital mortality and hospital survivors.

\begin{tabular}{|l|c|c|c|}
\hline \multicolumn{1}{|c|}{ Factor } & $\begin{array}{c}\text { Hospital } \\
\text { mortality } \\
(\mathbf{N = 7 )}\end{array}$ & $\begin{array}{c}\text { Hospital } \\
\text { survivors } \\
(\mathbf{N}=48)\end{array}$ & P-value \\
\hline AF & $\begin{array}{c}6 / 25(24 \%) \\
1 / 30(3.3 \%)\end{array}$ & $\begin{array}{c}19 / 25(76 \%) \\
29 / 30(96.7 \%)\end{array}$ & 0.002 \\
\hline NYHA Class & $3.57 \pm 0.53$ & $3.18 \pm 0.39$ & 0.02 \\
\hline LVESD (cm) & $4.86 \pm 1.29$ & $4.05 \pm 0.78$ & 0.02 \\
\hline LVEDD (cm) & $6.94 \pm 1.00$ & $6.01 \pm 0.83$ & 0.01 \\
\hline EF (\%) & $55.71 \pm 3.2$ & $66.35 \pm 6.17$ & 0.005 \\
\hline FS (\%) & $30.14 \pm 3.02$ & $33.66 \pm 2.98$ & 0.005 \\
\hline MPAP (mm Hg) & $68.4 \pm 5.8$ & $52.3 \pm 4.6$ & 0.001 \\
\hline Ischemic time (minutes) & $108.85 \pm 12.2$ & $105.2 \pm 10.8$ & N.S. \\
\hline Bypass time (minutes) & $160.4 \pm 22.2$ & $159.3 \pm 13.4$ & N.S. \\
\hline Ventilation hours & $27.0 \pm 27.3$ & $10.1 \pm 3.8$ & 0.000 \\
\hline Weaning (N=53): easy \& moderate & $2 / 42(4.8 \%)$ & $40 / 42(95.2 \%)$ & 0.000 \\
\hline difficult & $5 / 11(45.5 \%)$ & $6 / 11(54.5 \%)$ & \\
\hline MV preservationv +ve & $1 / 31(3.2 \%)$ & $30 / 31(96.8 \%)$ & 0.01 \\
\hline -ve & $6 / 24(25 \%)$ & $18 / 24(75 \%)$ & \\
\hline HCU stay days (53 case) & $4.00 \pm 2.8$ & $4.41 \pm 0.76$ & N.S \\
\hline Hospital stay days & $8.42 \pm 5.56$ & $18.1 \pm 5.69$ & 0.000 \\
\hline
\end{tabular}

N: Number of patients, AF: Atrial fibrillation. NYHA: New York Heart Association, LVESD: left ventricular end systolic diameter, LVEDD: left ventricular end diastolic diameter, EF: ejection fraction, FS: fractional shortening, MPAP: mean pulmonary artery pressure, and MV: Mitral valve, NS: Nonsignificant, $P<0.05$ considered significant. 
Table 4. Comparison of different variables between late moralities and late survivors.

\begin{tabular}{|c|c|c|c|c|}
\hline \multicolumn{2}{|l|}{ Factor } & $\begin{array}{l}\text { Late mortility } \\
\qquad(N=5)\end{array}$ & $\begin{array}{l}\text { Late survivors } \\
\qquad(\mathrm{N}=43)\end{array}$ & p-value \\
\hline \multicolumn{2}{|l|}{ NYHA functional class } & $3.12 \pm 1.08$ & $1.62 \pm 0.84$ & 0.002 \\
\hline MV preservation & $\begin{array}{l}+\mathrm{ve} \\
\text { - ve }\end{array}$ & $\begin{array}{c}0 / 29(0 \%) \\
5 / 19(26.3 \%)\end{array}$ & $\begin{array}{c}29 / 29(100 \%) \\
14 / 19(73.7 \%)\end{array}$ & 0.003 \\
\hline Post op. Complication & $\begin{array}{l}+\mathrm{ve} \\
-\mathrm{ve}\end{array}$ & $\begin{array}{c}5 / 5(100 \%) \\
0 / 5(0 \%)\end{array}$ & $\begin{array}{c}9 / 43(20.5 \%) \\
34 / 43(79.1 \%)\end{array}$ & 0.001 \\
\hline Arrhythmia & $\begin{array}{l}\text { +ve } \\
\text {-ve }\end{array}$ & $\begin{array}{l}3 / 5(60 \%) \\
2 / 5(40 \%)\end{array}$ & $\begin{array}{c}6 / 43(14 \%) \\
37 / 43(86 \%)\end{array}$ & 0.012 \\
\hline $\operatorname{LVESD}(\mathrm{cm})$ & & $4.80 \pm 1.05$ & $3.87 \pm 0.92$ & 0.001 \\
\hline LVEDD $(\mathrm{cm})$ & & $6.21 \pm 1.12$ & $5.71 \pm 0.77$ & 0.02 \\
\hline $\mathrm{EF}(\%)$ & & $53.91 \pm 2.11$ & $69.64 \pm 5.07$ & 0.003 \\
\hline FS (\%) & & $28.14 \pm 2.02$ & $35.92 \pm 2.92$ & 0.001 \\
\hline MPAP $(\mathrm{mm} \mathrm{Hg})$ & & $62.2 \pm 6.4$ & $47.3 \pm 4.8$ & 0.001 \\
\hline
\end{tabular}

NYHA: New York Heart Association, MV: Mitral valve, LVESD: left ventricular end systolic diameter, LVEDD: left ventricular end diastolic diameter. EF: ejection fraction, FS:, fractional shortening, and MPAP: mean pulmonary artery pressure.

Fig 1. Survival function according to the preoperative NYHA functional class.

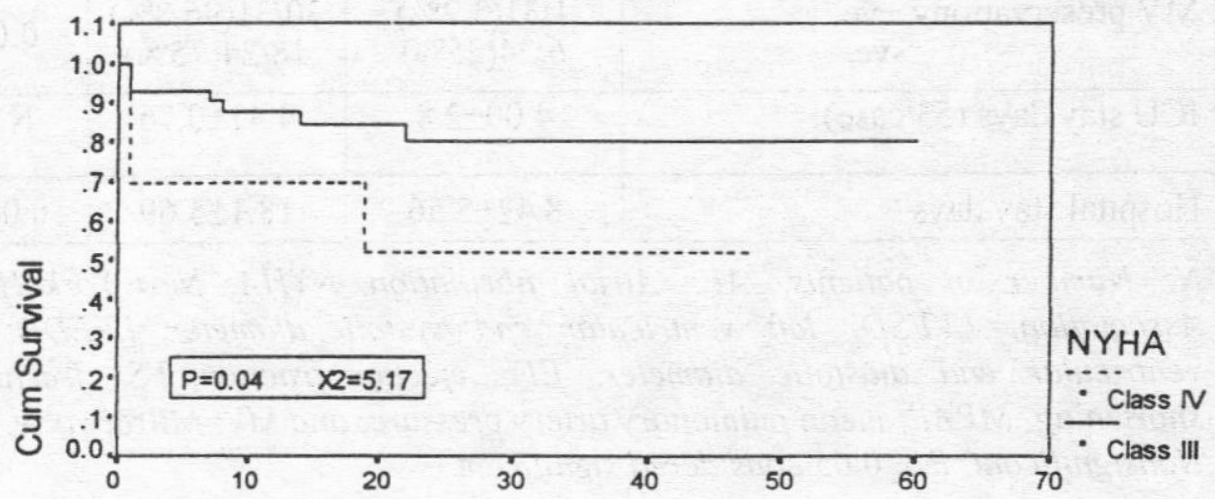

follow-up in months 
Fig 2. Survival function accorging to the postoperative NYHA functional class.

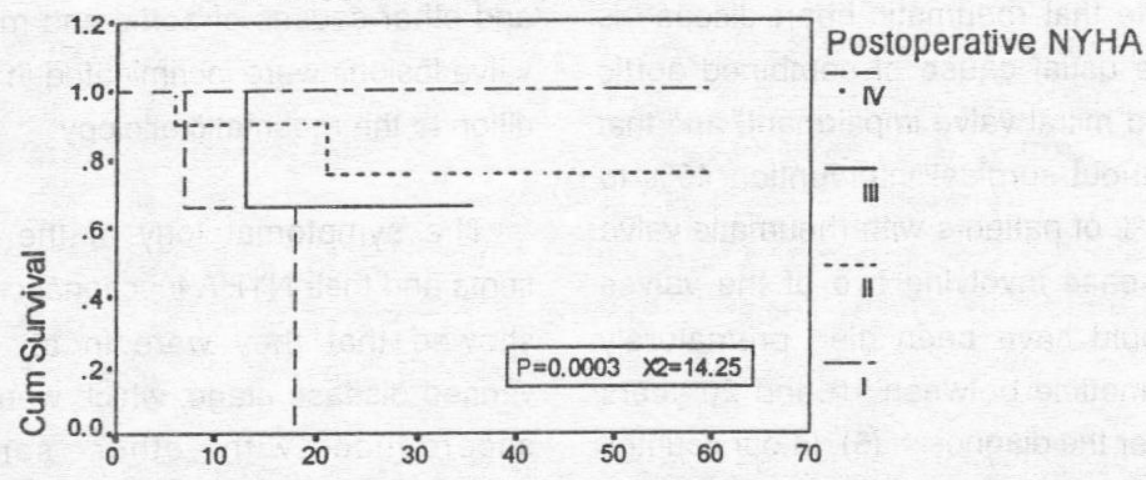

follow-up in months

Fig 3. Acturial survival after combined mitral and aortic valve replacement.






\section{DISCUSSION}

Previously reported studies indicate that rheumatic heart disease is the usual cause of combined aortic and mitral valve impairment, and that without surgical intervention $40 \%$ to $50 \%$ of patients with rheumatic valve disease involving two of the valves would have been died prematurely sometime between 10 and 20 years after the diagnosis. (5). In our country, rheumatic valvular heart disease form $80 \%$ of patients seen in cardiac medical or surgical clinics and pose special problems as they usually present late with bad ventricular function, severe pulmonary hypertension, liver failure or bad nutritional and general condition. Fifty percent of them are either below the age of 20 , or women in the childbearing period, and when first seen, many of these patients have significant polyvalvular lesions (6).

The mean age of our patients was around 30 years and $36.4 \%$ of them (20 patients) were below the age of 25 years. Most of our patients $(92.7 \%)$ had a definite history of previous rheumatic fever. This matches with the demographic data of patients from developing countries (2.6), but differs from those of patients from western countries $(1,3,5,7,8)$ where the mean age was around 50 years and other causes of aortic and mitral valve lesions were incriminated in addition to the rheumatic etiology.

The symptomatology of the patients and their NYHA functional class showed that they were in an advanced disease stage, which went in accordance with other series $(2,3,5,6)$. Also the preoperative echocardiographic data revealed markedly enlarged left ventricular dimensions with low ejection fraction and fractional shortening of most of the patients, same like what was reported by other authors $(2,3,6,8)$.

The reported incidence of hospital mortality after double valve surgery shows a considerable variability between $5 \%$ and $15 \%(2,5,6,8-11)$. In our study, there were two cases of operative mortality $(3.6 \%)$ one of them was performed on emergency basis, same finding seen by other authors $(2,9-11)$ who reported emergency surgery as a high risk factor. The other patient was having markedly impaired left ventricular functions preoperatively. This factor was also stressed upon by many authors (2,511) as a predictor for operative mor- 
tality in double valve surgery.

With the other five hospital deaths in our series $(9.1 \%)$ total mortality is $12.7 \%$ which compares to other series (9-11).

The cause of hospital death in our series was persistent myocardial failure in 2, cerebrovascular accident in one, ventricular arrhythmia in one, and multiple organ failure in one, which is in accordance to the main causes of hospital mortality reported by other authors $(2,5-11)$ who also stated that double valve replacement itself appears to be an incremental risk factor for death compared to isolated replacement of the mitral or aortic valve. Also operation performed on emergency basis carries a higher mortality rate than ones on elective basis as stated by many authors $(2,6,9-11)$. Our only case of emergency double valve replacement died on table.

On analysis of the preoperative variables that might have been of effect on the outcome of patients and comparing between the hospital survivors and hospital mortality the age, sex, duration of symptoms, and the cardiothoracic ratio were of no signifi- cance. Although age was identified as a risk factor for hospital mortality by some authors $(3,8,9,12,13)$, yet it was not in our series and others $(2,5,6)$ and this is explained by the younger age of our patients and absence of concomitant coronary artery diseases as seen in other series .

The factors found to be of significance as predictors for hospital mortality in our series were the preoperative presence of $\mathrm{AF}$, high functional class (NYHA III or IV), preoperative left ventricular parameters (echocardiographic LVESD, LVEDD, $E F, F S$, and pulmonary artery pressure).

The presence of AF was proved by us and others $(2,3,5,6,8,9,14)$ to be a significant factor for hospital mortality after double valve replacement. Also the advanced NYHA functional class and the more disability of the heart, the more the operative risk, as other authors stated $(5,6,9,14)$. This factor was found to be significant in our study with a P-value of 0.002 .

The preparative left ventricular parameters as elicited by echocardiogrophy was stressed by many authors $(2,3,5,6,9,13,14)$ to be the 
most important predictor for out come in double valve replacement. The same finding was observed in our study as the LVESD, LVEDD, EF, and FS were all of significance with EF and $F S$ of high significance ( $P$. value of 0.005). The SWT, PWT and left atrial diameter were of no significance.

The elevated pulmonary blood pressure preoperatively was found by John et al (2) and others $(6,7,9,14,15)$ to be a strong predictor of mortality in double valve surgery. The seven mortalities in our series were having a MPAP $>60 \mathrm{~mm} \mathrm{Hg}$. with a highly significant $P$ value of 0.001 compared to a MPAP of $<60 \mathrm{~mm} \mathrm{Hg}$ in the survivors.

Preservation of posterior mitral valve apparatus was usually performed in our cases of double valve replacement whenever possible. It was performed in 31 patients to maintain the geometry of the left ventricle and help improve the left ventricular performance according to the recommendation of David (16), and we found it to be of significance ( $P$. value 0.01 ) in detecting operative and early mortality as 6 of our 7 moralities had a conventional resection of all the mi- tral apparatus without preservation, same finding of other authors $(2,6,10,11)$.

The high significance of the need for higher doses of inotropic support, difficult weaning off bypass and prolonged mechanical ventilation should be considered as consequences of the patients referred to us in critical condition rather than being a cause of mortality. Other investigators $(2,6,8,10,11)$ mentioned this same statement.

Throughout the period of 5 years follow up of our patients (48 patients) the functional class of most of them $(81.3 \%)$ had markedly improved to class I or II, which compares favorably with other reports $(2,6,9,13-15)$ and confirms that function improvement with mitral aortic valve surgery to be more or less the same as with isolated valve surgery (13-15), and that these patients enjoyed not only a complication free status but their life style also significantly improved (5).

Complications occurred in $29.2 \%$ of our patients throughout the follow up period which is comparable to other reports $(2,3,6-8,13)$, The most serious ones were due to late endocardi- 
tis in five patients (10.4\%) and persistent myocardial failure in four $(8.3 \%)$. Other investigators $(2,6,9,14)$ also mentioned this. The three cases of thromboembolism and the two of anticoagulation related haemorrhage were non fatal and managed conservatively with no consequences, as occurred with others $(5,117,18)$. There was no cases of structural failure or paravalvular leak in our series, and we believe like others $(2,5,6,9)$ that interrupted horizontal mattress sutures are a sine qua non in its prevention and provides better valve stability.

Late mortality occurred in five of our patients, $(10.4 \%)$, three due to endocarditis and two due to progressive heart failure, same causes of late mortality recorded by many authors $(2,3,5,6,9,12,13,15,18)$.

Many authors have mentioned that prolonged operation times and the presence of two prostheses might be responsible for the increased incidence of prosthetic valve endocarditis after double valve replacement than after isolated mitral or aortic valve replacement $(3,9,12,14,15)$.

In comparison between late mortalities and survivors it was interesting to find that all patients who died late had no much improvement in their NYHA functional status postoperatively and remained in either class III or IV. All of them were in the group in wh =m mitral valve apparatus was not preserved, and all of them had postoperative late complications, that progressed to death. Their left ventricular echocarodiographic data particularly ejection fraction and fractional shortening did not improve post operatively and their MPAP persisted elevated over $60 \mathrm{~mm} \mathrm{Hg}$ after surgery. The P-value of these factors was highly significant (Table 4).

Previous studies on multivalvular heart disease recommended primary multivalvular surgery before severe symptomatic and functional deterioration occurs in order to prevent irreversible myocardial damage which is especially common in patients with combined aortic and mirtal incompetence $(9-12,18)$ and that failure to recommend early surgery to the high risk patient is a lost opportunity to help patient who would have a better chance with surgery (5).

The actuarial survival of our patients at 1 and 5 years was $83.04 \%$, and $73.79 \%$ respectively (Fig.3),

MANSOURA MEDICAL JOURNAL 
which is comparable with the results of follow up of other authors $(5,7,8,11$. 14,18).

\section{Conclusion:}

In conclusion, this study showed that combined mirtal and aortic valve replacement in our series is an operation that can be performed with a mortality and morbidity not substantially higher than what is reported, and we recommend it to be performed as early as possible to patients with double valve lesion before irreversible myocardial damage occur.

The main factors affecting early operative outcome are the advanced NYHA functional class, low left ventricular performance, elevated pulmonary artery pressure, and presence of atrial fibrillation.

The factors that control intermediate and late outcome after combined mitral and aortic valve replacement are the non improvement of the NYHA functional class III \& IV, development of valve related post operative complications, development of arrhythmias, and persistence of low left ventricular performance.

The technique of preservation of Vol. 32, No. 1 \& 2 Jan. \& April, 2001 mitral valve apparatus (whenever feasible) is of significant effect on early and intermediate outcome after combined mitral and aortic valve replacement.

\section{REFERENCES}

1- Soler JS, Galve E (2000) : Valve disease. Worldwide perspective of valve disease. Heart; 83: 721.

2- John S, Ravikumar E, John CN, Bashie VV (2000) : 25ñyear experience with $456 \mathrm{com}$ bined mitral and aortic valve replacement for rheumatic heart disease Ann Thorac Surg; 69: 167.

3- Bortolatti U, Milano A, Testalin L, TarsiV, Mazzucco A, GallucciV (1991) : Influence of type of prosthesis on late results after combined mitralaortic valve replacement. Ann Thorac Surg; 52: 84.

4- Edmonds $H$ L, Clack RE, Gohn LH, Grunkmeir GI, Miller DC, Weisel R D (1996) : Guidelines for reporting morbidity and mortality after cardiac valvular operations. 
cardiac valvular operations.

J Thorac Cardiovasc Surg;

112: 708.

5- Arom KV, Nicoloff DM, Kersten TE, Northrup WF, Lindsay WG, Emery RW (1989) : Ten year follow up study of patients who had double valve replacement with the St. Jude Medical prosthesis. J Thorac Cardiovasc Surg; 98: 1008.

6- Abdelkarim M, Hassouna A, Abdelrahman $\mathrm{H}$, Mansour KH (1998) : Independent prediction of outcome after triple valve surgery. $\mathrm{J}$ of Egypt Society of Cardio Thoroc Surg; 6(2): 21.

7- Brown PS, Roberts CS, Mc Intosh CL, Swain JA, Clark RE (1993) : Relation between choice of prosthesis and late outcome in double valve replacement. Ann. Thorac Surg; 55: 631.

8- Fiore AC, Swartz MT, Sharp TG, et al (1995) : Double valve replacement with Meditronic Hall or St. Jude valve. Ann Thorac Surg; 59: 1113.

9- Kirklin JW, Barratt-Boyes BG (1993) : Combined aortic and mitral valve diseases with or without tricusped valve disease. In Cardiac Surgery, 2 nd edition vol. 2 edited by Churchil Livingstone, New York - Edinburgh - London - Melbourne ñ Tokyo. -573.

10- Christakis JT, Weisel RD, David TE (1988) : Predictors of operative survival after valve replacement. Circulation; 78: 25.

11- Teoh KH, Christakis JT, Weisel RD, et al (1987) : The determinants of mortality and morbidity after multiple valve operations. Ann Thorac Surg; 43: 353.

12- Galloway AC, Grossi EA, Baumann FG, et al (1992) : Multiple valve operation for advanced valvular heart disease, results and risk factors in 513 patients. J Am Coll Cardiol; 19: 725.

MANSOURA MEDICAL JOURNAL 
13- Mueller XM, Tavaerai HT, Stumpe F (1998): Long term results, of mitral . aortic valve operations. J Thorac Cardiovas Surg; 115: 1298.

14- Stephenson LW, Edie RN, Hasken AH, Edmunds LH (1984) : Combined aortic and mitral valve valve replacement, changes in practice and prognosis. Circulation; 69: 640 .

15- Armenti F, Stephenson LW, Edmunds LH (1987) : Simultaneous implantation of the St Jude medical aortic and mitral prostheses. J Thorac Cardiovasc Surg; 94: 733.

16- David TE (1986) : Mitral valve re- placement with proservation of chordae tendinae. Rationale and technical considerations. Ann Thorac Surg; 41: 680 .

17- Jameison WRE, Miyagishima RT, Tyers FO, Lichienstein SV, Munro Al, Burr LH (1997): Bileaflet mechanical prostheses in mitral and multiple valve replacement surgery, influence of anticoagulant management on performance. Circulation, 96: 134.

18- Lindblom $D$, Lindblom U, Aberg B (1988) : Long term clinical results, after combined aortic and mitral valve replacement. Eur J Cardio Thorac Surg; $2: 347$. 


\section{الاستبدال المشترك للصمامين الميترالى والأورطى}

\section{العوامل المؤثرة على النتائج المبكرة ومتوسطة المدى بعد الجراحة}

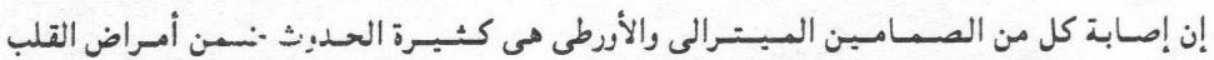

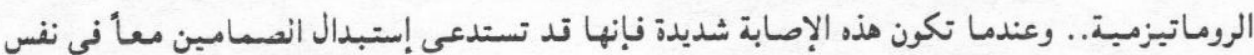
الوقت. وتناقش هذه الدراسة العوامل المؤثرة على النتائج المبكرة ومتوسطة المدى بعد الإستبدال المشترك

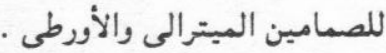

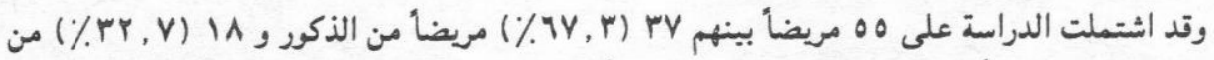

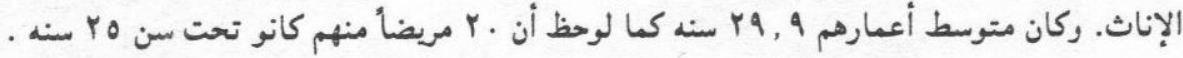
وقد حدثت سبع وفيات بالمستشفى منهم إثتـان أثناء العملية. وكانت العوامل التى وجد أن لها دلالة

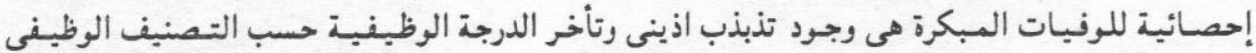

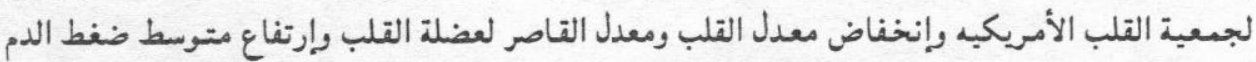
بالشريان الرئوى.

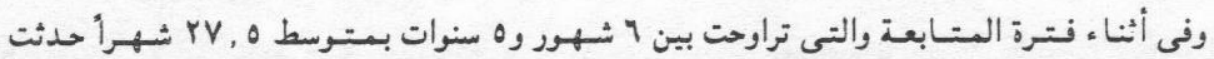

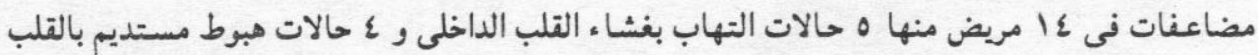

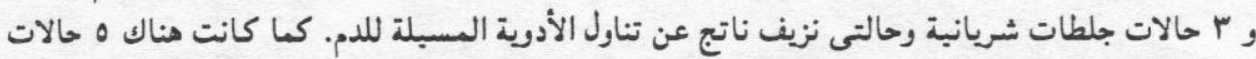

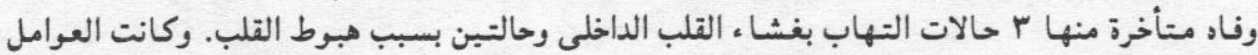

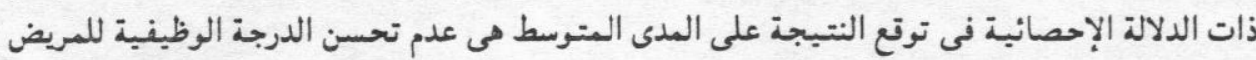

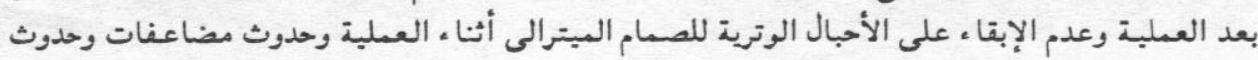

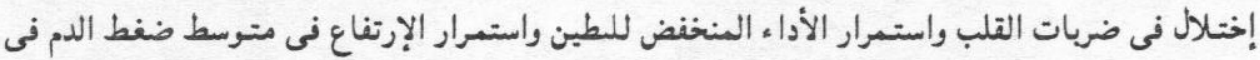
الشريان الرئوى.

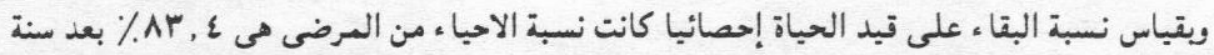

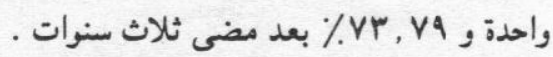

وأستخلص من البحث أن عـلية الاستبدال المشترك للصمامين الميتـرالى والأورطى هى عمليـة ذات وفيات أر مضاعفات لاتزيد كثيراً عن مثيلاتها المسجلة فى الهراكز الأخرى. ونوصى بإجراء هذه العـلية

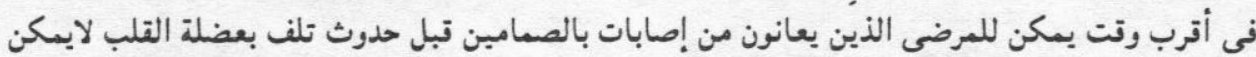

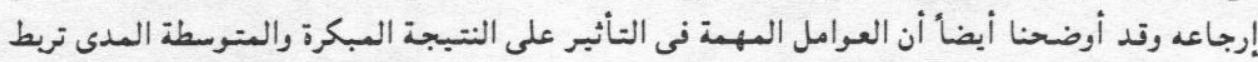

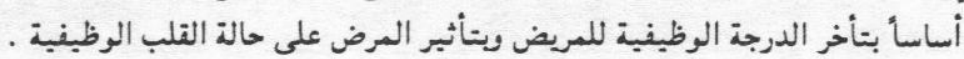


